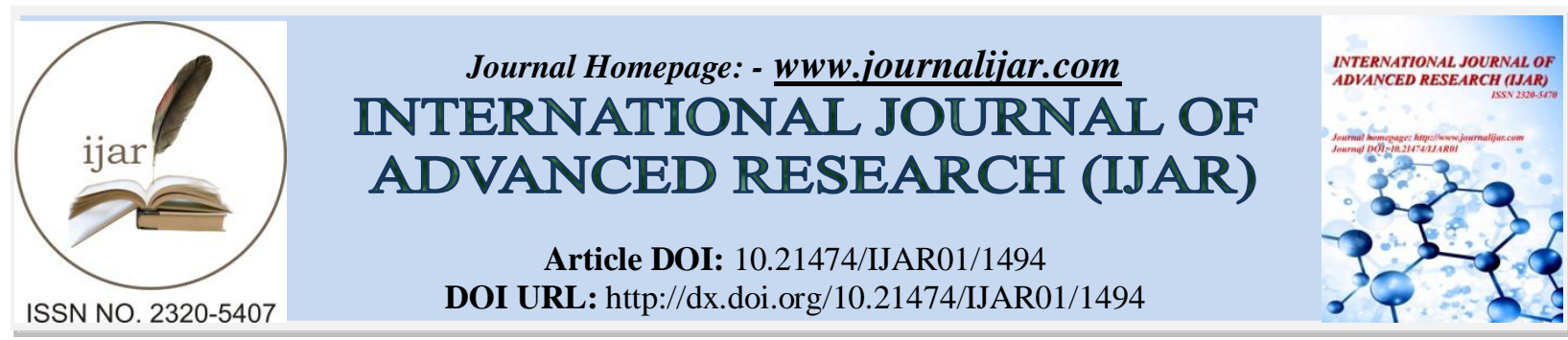

RESEARCH ARTICLE

\title{
EFFECT OF SOCIAL MEDIA ON INDIVIDUALS' ATTITUDE AND COMMUNICATION; THAT HOW IT (SOCIAL MEDIA) CREATES AN ATTITUDE TOWARDS HIRING; EVIDENCE FROM STUDENTS/YOUNGSTERS OF PUNJAB, PAKISTAN.
}

\author{
Abdul Basat ${ }^{1}$, Aadil Amjad ${ }^{2}$ and Mohsin Raza ${ }^{3}$. \\ 1. MS scholar, National college of Business Administration and Economics (NCBA\&E), Pakistan. \\ 2. Lecturer, University of Gujrat, Pakistan.
}

\section{Manuscript Info}

Manuscript History

Received: 12 July 2016

Final Accepted: 22 August 2016

Published: September 2016

Key words:-

\section{Abstract}

Purpose:-The purpose of this research study is to elaborate the reasons why students/youngsters are fond of social networks, how they create an attitude towards hiring and helpful for them in enhancing their communication and interaction ability with other people that belong to different cultures i.e. Are there any chances that their ability to communicate things can be changed by using social network that train them for better attitude or not?

Design/methodology:- We are using the inquiry mode of research in which we use the qualitative approach. Our population is Punjab province' we select our sample from some Major cities of Punjab province i.e Gujranwala, Sialkot and Gujrat. The sampling technique we are using is the proportionate stratified sampling. Such sampling technique in which we divide our sample size in equal proportion for both male and female students. First we visit colleges that are giving different short courses; we will survey them and interview the students' and other youngsters. Then fill up the questionnaire from them we prepared regarding the above mentioned topic.

Findings:- The result shows that there is a serious impact of the social network on the youngsters' communication that definitely leads to the improvement in their interaction with other peoples belong to different cultures and thus; it will enable them to interact in an appropriate way as they know how to speak and behave at different places. Moreover; it is found that social network plays a vital role in building an attitude that leads towards the success to be hired.

Research limitation:- A limitation is basically the transversal design of the study that leads to the future research work on the topic.

Practical implications:- This study basically contributes a vital role to the young generation who are fired due to lack of disseminating the ideas, thoughts or for those who are surfing failure after several interviews. Moreover to find the appropriate site in the meantime is another practical implication as youngsters' browse internet but they do not know which will be best so this study gives them tactics that how they learn for their attitude.

Copy Right, IJAR, 2016,. All rights reserved. 


\section{Introduction:-}

Technology is getting advanced day by day. With this the life become comfort in which you can easily get what you want. By the efforts of IT professionals the technology is getting highly advanced but complex as a single individual has so many options that make his need complex and the individual find it difficult to find out the solution of his/her need.

A part of this technology is the online social networks that are moving fast to become the part of an individual life. Social network is something that enables the individual to be part of the national and international society. These social networks include Facebook, twitters, yahoo chat boxes, Bing, Google chat rooms, etc. on one way the social network connect you with multicultural societies and on other way its develops different skills regarding communication, interactions, behaving and many more.

This research is basically done on the basis to find out the relation of the online social network with the youngsters communications and their abilities to interact with the multicultural environment individuals, how it is effective for an individual to become a successful candidate in interview. As now a days companies prefer who is all-rounder in terms of communications, working \& by look as well. People say that first impression is the last impression. And to verify that how the impression is being improvises by the communication and social networking as well.

We select our sample from Gujrat, Gujranwala and Sialkot city' where there is a huge number of students and youngsters reside; the Gujrat city has its own public university named as Gujrat University and has the Swedish technology training institutes as well. Students from different cities come here to get education and use hostels as well so we found to conduct our research in these cities.

This research is also conducted to find out the impacts of online social network that either they develop skills in individuals to compete in national and international market of jobs where there is a huge competition to achieve basic necessities of life.

Now a days the communication skills and interaction abilities are necessary to achieve job from huge competition if you have good skills then you will be able to achieve the future goals. As future meant to those who start to think from today. So, we are trying to find out the relation or contribution of online social network in enhancing the skills of the individual.

Our research variables i.e.Online Social Network, youngster's communications and individual interactions are the key predictors for this research and on the basis of this we are going to find out how social networks build an attitude. As now a day we have found that youngsters are fond of social network applications and have interactions with new people and that is how we found the relationship among them which is described in the paper ahead.

\section{Purpose of Study:-}

This research is basically done on the basis to find out the relation of the online social network with the youngsters communications and their abilities to interact with the multicultural environment individuals, how it is effective for an individual to become a successful candidate in interview. As now a days companies prefer who is all-rounder in terms of communications, working \& by look as well. People say that first impression is the last impression. And to verify that how the impression is being improvises by the communication and social networking as well.

\section{Problem Statement:-}

The Research question is to find out the "Effect of Social Media on the Communication of an Individuals that how it creates an attitude towards hiring”

Our population size is the whole Punjab and our sample size is the Gujrat city where there is a huge number of students and youngsters reside; the Gujrat city has its own public university named as Gujrat University and has the Swedish technology training institutes as well. Students from different cities come here to get education and use hostels as well so we found to conduct our research in Gujrat city as our sample size. 


\section{Significance and relationship of Variables:-}

Now a days the communication skills and interaction abilities are necessary to achieve job from huge competition if you have good skills then you will be able to achieve the future goals. As future meant to those who start to think from today. So, we are trying to find out the relation or contribution of online social network in enhancing the skills of the individual.

Our research variables i.e.Online Social Network, youngster's communications and individual interactions are the key predictors for this research and on the basis of this we are going to find out how social networks build an attitude. As now a days we have found that youngsters are fond of social network applications and have interactions with new people and that is how we found the relationship among them which is described in the paper ahead.

\section{Objective:-}

This research is also conducted to find out the impacts of online social network that either they develop skills in individuals to compete in national and international market of jobs where there is a huge competition to achieve basic necessities of life.

\section{Literature review:-}

The above mentioned topic has already been studied by various researchers in different categories who aim to examine different aspects of the employee's attitude in organization and other fields. The popularity of the social networking is increased day by day, by recruiters, as they received positive attention from the people. The role that has been identified a specific attraction mechanism, the recruiterstry to create weak ties for the candidates' . The researchers identify branding, data specificity, transparency as mechanisms that recruiters use to screening and attracting candidates towards their websites or webpages.(Nickolas Ollington, Jenny Gibb, Mark Harcourt,2013).Recruitment agencies works as intermediary between organization and candidates who are interested, they seek potential candidates who search for work opportunities (Buechler, 2010; Marchal et al., 2007).

Those agencies select candidate on general criteria that focus on the academia qualifications as required in the specifications of the job(Chapman and Webster, 2013.).

The candidates' online recommendations for various activities are highlighted by the other consumers as he/she find it authentic as compared to the advertisement that has been animated on the screen. The researcher also examines that how it will be useful for the manages to recommend the candidate online by watching or screening certain characteristics of the recommendation. Moreover; how the consumer takes the product that is displayed on the screen. (Elizbieta Lepkowska- White, 2013)

The attitude is deeply attached to the psychology of a person to enlighten the psychological contract of an employee due to change in the values of the organization. Sudden changes, threating, pressurizing the subordinates leads to psychological effects of the employee that start to reduce his confidence level and the desired productivity cannot be achieved, the way employee adjust himself in the changing environment all depends upon the psychological contraction of the employee. (Sjoerd van der Smissen et al., 2013). The new workplace reality will significantly redefine employment relationships and have an impact on individuals' psychological contracts (Guest, 2004; Freese, 2007; van den Heuvel and Schalk, 2009; Chaudry et al., 2011).

More than a few employer features are positive for business reputation, which is related to desirability of probable employees. Researchers' result suggest that origination, psychosomatic value, solicitation value, and use of social media positively relate to corporate standing, which in turn is linked in a positive intentions to apply for a career. Psychosomatic value, which is the strongest prognosticator, is also directly related to intentions to apply for a job. (Anne-MetteSivertzenet al.,2013 Vol. 22 Iss: 7, pp.473 - 483)

Researchers have also found that there are three different communications strategies that are being used depending on the scope of internet use and the extent to which the companies utilise relationship marketing. Small or decentralized companies use the personalized relationship communication strategy. Large corporations have the alternative of using either the mass rapport communication stratagem or the mass operation communication strategy (Stefan Lagrosen, 2005) 
It has also been found that when the attitude towards hiring is effected by various aspects in which one of them is the commitment that has a positive sway on customer gratification and shrinks risk acuities. There is a lesser amount of support for prototypical in which contentment increases commitment and shrinks alleged risk.

We are actually reviewing the relation of online social networks that how it affects the youngster communication skills and their ability to interact in multicultural environment.The variables we took never studied before for the youngsters' of Gujranwala, Sialkot and Gujrat city in Pakistan that is why we decided to get effective result from these areas.

\section{Methodology:- \\ Data description:-}

The data we collect from our sample size shows significant results that the social network have vital role in their lives as it becomes the need of the hour without which it's quite difficult for the people to survive in such an advanced era that moving fast towards new horizons of the technology and living standards of the people. Youngsters believe that the social networks enhance their abilities of speaking, communicating and interaction with other individuals that basically belongs to different cultures. Moreover following are the hypothesis we made for our research that shows the following results;

H1: Online social network enable youngsters to understand the different cultures of individuals.

Result: Yes, the social network enables them to understand the cultures of individuals with the help of which they behave according to certain possible circle of communication and interaction.

H2: Online social network helps youngsters to behave, communicate in a good manner in multicultural environment.

Results Yes, such network helps the young generation that start their work helps them in communication at work place or outside the workplace.

Thus from the results we found that there is a significant relation of the social network with the youngsters communication and their ability to interact in a multicultural environment. Thus; we are accepting $\mathbf{H 1}$ as there is a positive relation between the variables and rejecting Ho.

\section{Type of research:-}

We are using the inquiry mode of research in which we use the qualitative approach. That approach provides us with the primary data through questionnaires we fulfilled by the young volunteers.

\section{Data source:-}

The data source is basically the students of the colleges, universities and other young generation aging between $\mathbf{1 8}$ 30 years. They were the primary source of data collection and enable us to compile results of our research work.

\section{Sampling technique:-}

The sampling technique we are using is the proportionate stratified sampling. In this we defined a specific proportion to the sample size that consists of 150 volunteers. In which we are targeting 75 male volunteers and 75 females' volunteers for the questionnaire purpose.

Model specification:-

Following is the equation (model)of the research topic.

$$
\text { Y.C+ A.I.M.E }=\text { O.S.N }
$$

Abbreviation of the variable as follows;

Y.C $=$ Youngster Communication

A.I.M.E=Ability to Interact In Multicultural Environment

O.S.N= Online Social Network 
Variables:-

After model specification following are the different types of variables that help you to understand which one belongs to which category of the variable.

Dependent variable: youngster communication, ability to interact in multicultural environment Independent variable: online social network

Moderating variable: Internet marketing, marketing communication

Intervening variable: Increase skills to compete

Extraneous variable: Advancement in technology

Following we have the figure of our variables that represents their relationship with each other.

\section{Figure:-}

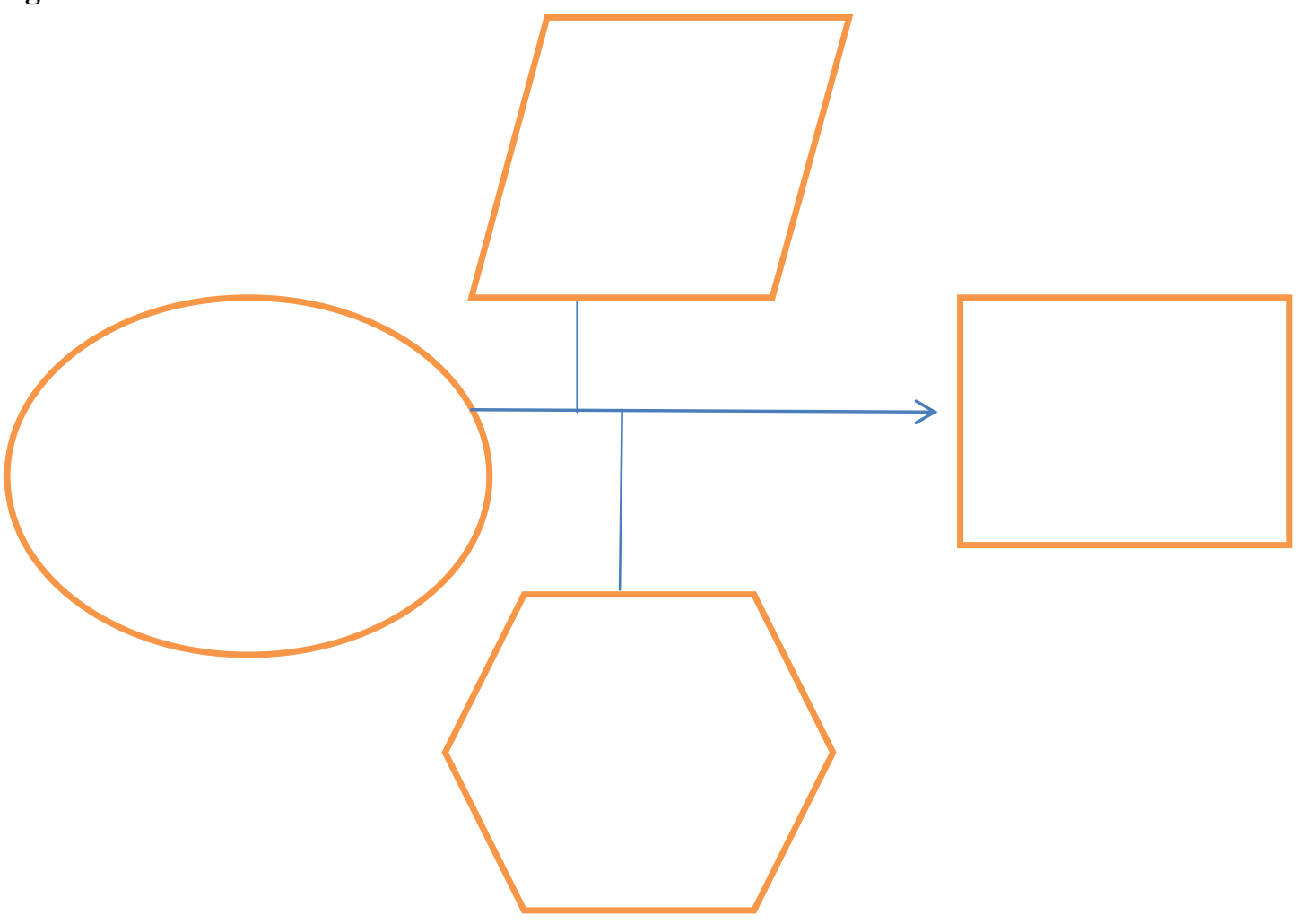

Operational definition of variables:-

Online Social Network:-

The network that enables you to interact with the society by using internet, termed as online social networks. They include Facebook, twitter, yahoo, etc. in short any network that connects you with other people online/using internet is online social network.

\section{Youngsters' Communication:-}

The ability of young generation to speak, communicate their thoughts, ideas on the ground level of the other individual belong to different religion, culture etc.

\section{Individual Interaction:-}

This refers to the capability of an individual to behave, interact with other individuals of different race, gender, religion and culture. 


\section{Results:-}

\begin{tabular}{|c|c|c|c|c|}
\hline \multicolumn{5}{|c|}{ Model Summary:- } \\
\hline Model & $\mathrm{R}$ & R Square & Adjusted R Square & Std. Error of the Estimate \\
\hline 1 & $.645^{\mathrm{a}}$ & .717 & .167 & .592 \\
\hline
\end{tabular}

a. Predictors: (Constant), Is the social network your first preference to find anything, Do you spend much of your time on social networks

\begin{tabular}{|c|c|c|c|c|c|c|}
\hline \multicolumn{7}{|c|}{ Coefficients $^{\mathrm{a}}$} \\
\hline \multicolumn{2}{|c|}{ Model } & \multicolumn{2}{|c|}{ Unstandardized Coefficients } & \multirow{2}{*}{$\begin{array}{c}\begin{array}{c}\text { Standardized } \\
\text { Coefficients }\end{array} \\
\text { Beta } \\
\end{array}$} & \multirow[t]{2}{*}{$\mathrm{t}$} & \multirow[t]{2}{*}{ Sig. } \\
\hline & & $\mathrm{B}$ & Std. Error & & & \\
\hline \multirow[t]{3}{*}{1} & (Constant) & .400 & 1.212 & & .330 & .773 \\
\hline & $\begin{array}{l}\text { Do you spend much of } \\
\text { your time on social } \\
\text { networks }\end{array}$ & .500 & .418 & .645 & 1.195 & .355 \\
\hline & $\begin{array}{l}\text { Is the social network your } \\
\text { first preference to find } \\
\text { anything }\end{array}$ & .000 & .418 & .000 & .000 & 1.000 \\
\hline
\end{tabular}

After getting this result we have found the social network is considered as top preference among individuals to become confident, communicative and produce an attitude that lead them towards hiring.

\section{Bar graph Of Results:}

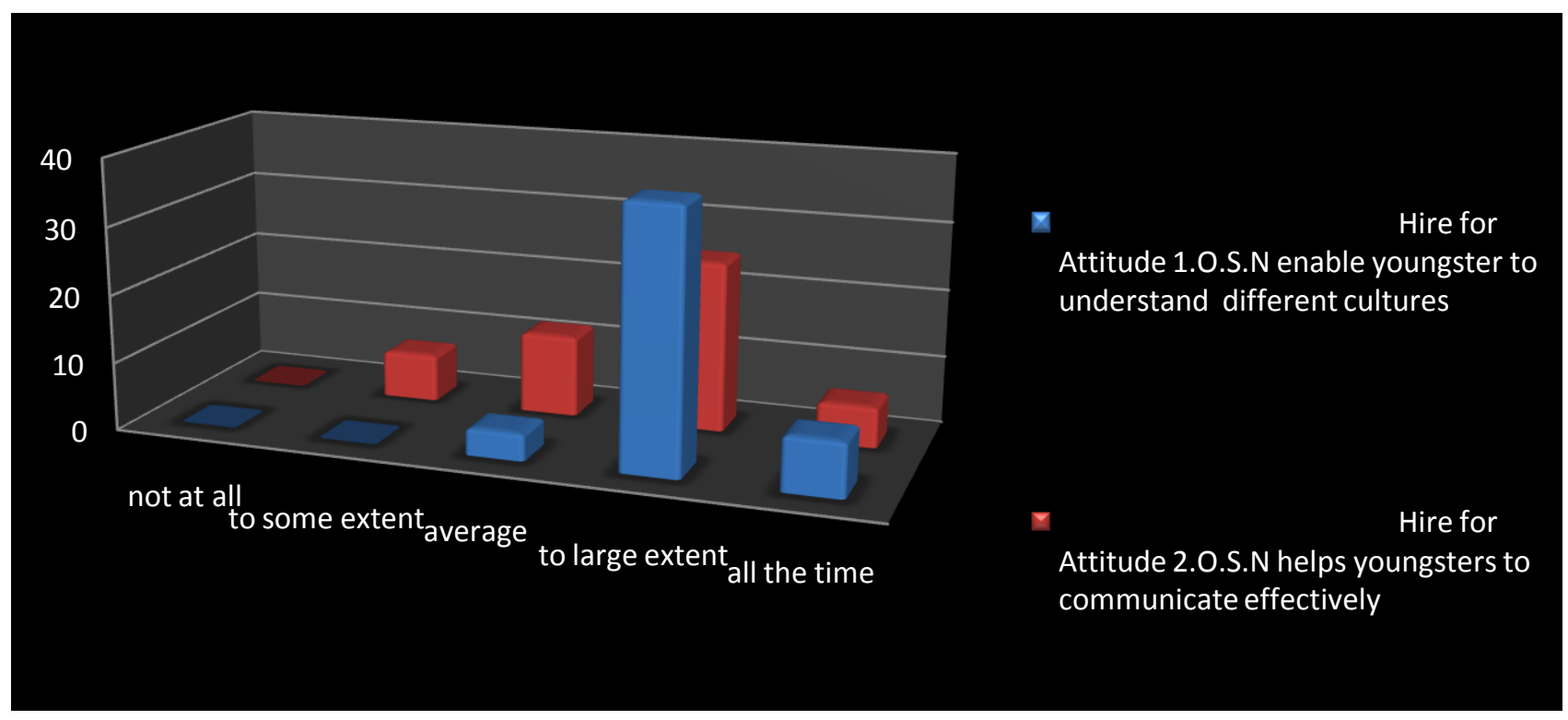




\section{Line Graph Of Results:}

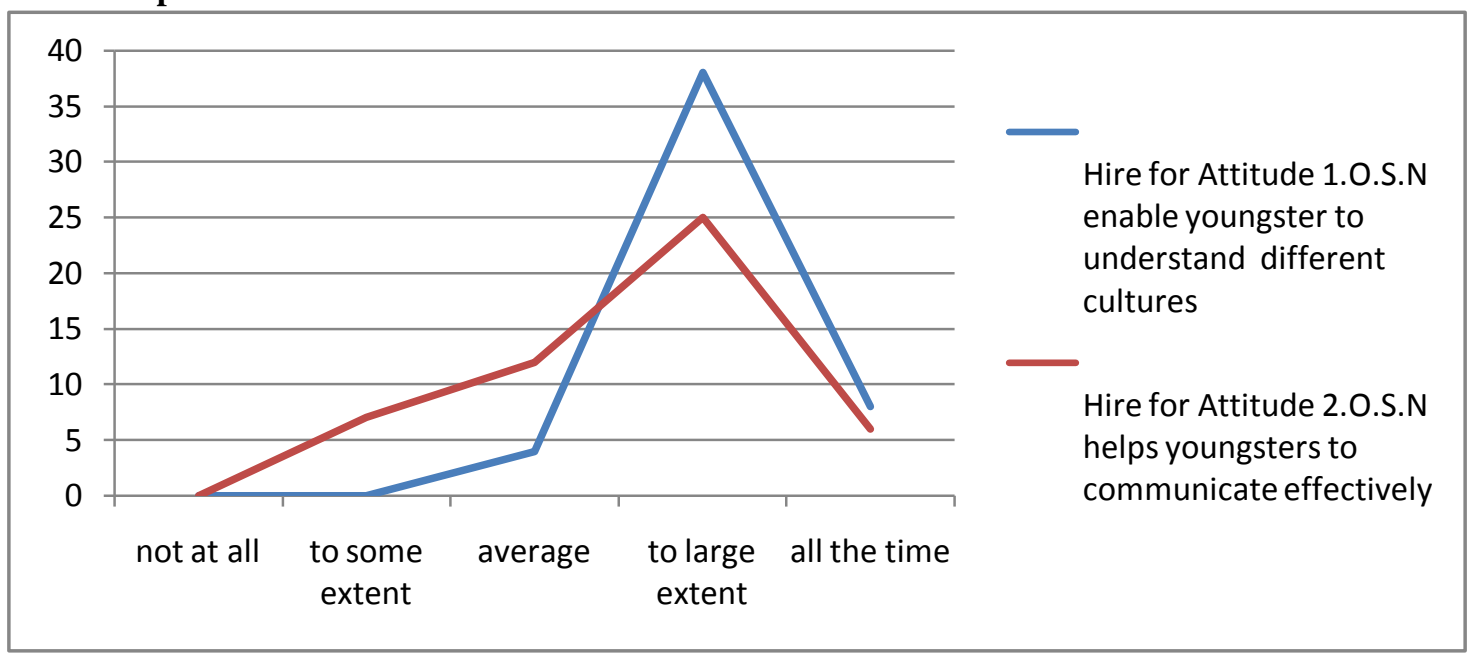

\section{Conclusion:-}

It is being concluded that online social network contributes a vital role in understanding cultures of people belonging to different demographic areas. They also enhance their skills i.e. communication and attitudes with others that are important at the workplace. As we are doing research on the effect of social network/media on an individual performance in an interview so it is found an important source to the introvert personalities that are talented but feel hesitation in communication. If a person has talent and skills to work but cannot express it, the skill will be useless. It is also being found that the most of candidate that get success are those who are expressive, communicative and describe the things in a good manner and are not just being hired but also get attractive packages from the organization. As we conduct and get data from the youngsters as well; it is found that the new generation are also fond of using latest social networking applications and make friends that belong to different demographic areas and cultures as well.

Moreover, other researchers also found that the social networking/media is not vital at initial level to enter in the organization, but it is plays an important role in getting success in the organization. There are various aspects that are to be considered and are linked with the social network; it would be the effect on the negotiation that is being made by the other individual or party.

Thus; the result indicate that it is a grim impact of the social network on the individual credibility to become efficacious in interview that definitely leads to the enhancement in their interaction with other peoples belong to different cultures and it will enable them to interact in an pertinent way as they know how to speak and behave at different dwellings as well.

\section{Limitations and future recommendations:-}

As we conduct this study in limited areas and on the students, for which we have choose a limited number of candidate from the population and ask questions from them by giving them a scenario related to usage of the social networks. As the students are fond of using latest gadgets and well aware of the different social applications. If this study has been done on the managerial level, ask the serving employees and retired employees, more precise and accurate results can be drawn from it.

In case of future recommendations, I would prefer to conduct this study on national level as different educational institutes are producing a good number of professionals every year and the jobs are not according to the graduate ratio. Fresh graduates serve for their careers more than two years after their graduation. 


\section{References:-}

1. Nickolas Ollington, Jenny Gibb, Mark Harcourt, (2013) "Online social networks: an emergent recruiter tool for attracting and screening", Personnel Review, Vol. 42 Iss: 3, pp.248 - 265

2. Sjoerd van der Smissen, René Schalk, Charissa Freese, (2013) "Organizational change and the psychological contract: How change influences the perceived fulfillment of obligations", Journal of Organizational Change Management, Vol. 26 Iss: 6, pp.1071 - 1090

3. Elzbieta Lepkowska-White, (2013) "Are they listening? Designing online recommendations for today's consumers", Journal of Research in Interactive Marketing, Vol. 7 Iss: 3, pp.182 - 200

4. Madeline M. Crocitto, Sherry E. Sullivan, Shawn M. Carraher, (2005) "Global mentoring as a means of career development and knowledge creation: A learning-based framework and agenda for future research", Career Development International, Vol. 10 Iss: 6/7, pp.522 - 535

5. Xiongfei Cao, XitongGuo, Douglas Vogel, Xi Zhang, (2016) "Exploring the influence of social media on employee work performance", Internet Research, Vol. 26 Iss: 2, pp.529 - 545

6. Nory Jones, Richard Borgman , EbruUlusoy , (2015) "Impact of social media on small businesses", Journal of Small Business and Enterprise Development, Vol. 22 Iss: 4, pp.611 - 632

7. Stefan Lagrosen, (2005) "Effects of the internet on the marketing communication of service companies", Journal of Services Marketing, Vol. 19 Iss: 2, pp.63 - 69

8. Jill M. Purdy, Pete Nye, P.V. (Sundar) Balakrishnan, (2000) "The Impact Of Communication Media On Negotiation Outcomes", International Journal of Conflict Management, Vol. 11 Iss: 2, pp.162 - 187

9. Liuhan Zhan, Yongqiang Sun, Nan Wang, Xi Zhang, (2016) "Understanding the influence of social media on people's life satisfaction through two competing explanatory mechanisms", Aslib Journal of Information Management, Vol. 68 Iss: 3, pp.347 - 361

10. LoetLeydesdorff, Mark William Johnson, Inga A. Ivanova , (2014) "The communication of expectations and individual understanding: Redundancy as reduction of uncertainty, and the processing of meaning", Kybernetes, Vol. 43 Iss: 9/10, pp.1362 - 1371

11. MihailoanRoșca, Andrei ClaudiuSarău, Andreea-Angela Vonțea (2015), Classifying Social Causes Derived from the Communication of CSR Initiatives Online: A Theoretical and Practical Approach, in Ana Adi , Georgiana Grigore, David Crowther (ed.) Corporate Social Responsibility in the Digital Age (Developments in Corporate Governance and Responsibility, Volume 7) Emerald Group Publishing Limited, pp.63 - 83

12. Aurélie Girard, Bernard Fallery, Florence Rodhain (2014), Integration of Social Media in Recruitment: A Delphi Study, in Tanya Bondarouk, Miguel R. Olivas-Luján (ed.) Social Media in Human Resources Management (Advanced Series in Management, Volume 12) Emerald Group Publishing Limited, pp.97 - 120

13. Anne-MetteSivertzen , EttyRagnhildNilsen, Anja H. Olafsen , (2013) "Employer branding: employer attractiveness and the use of social media", Journal of Product \& Brand Management, Vol. 22 Iss: 7, pp.473 483

14. VasjaRoblek, MirjanaPejić Bach, MajaMeško, Andrej Bertoncelj, (2013) "The impact of social media to value added in knowledge-based industries", Kybernetes, Vol. 42 Iss: 4, pp.554 - 568 